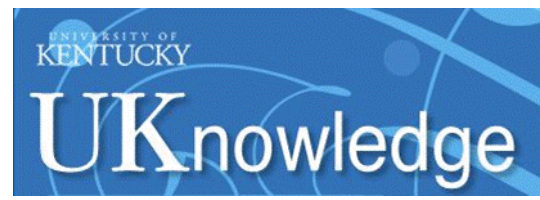

University of Kentucky

UKnowledge

$12-7-2017$

\title{
Synthesis and Characterization of Thermoresponsive Hydrogels Based on N-Isopropylacrylamide Crosslinked with 4,4'- Dihydroxybiphenyl Diacrylate
}

\author{
Shuo Tang \\ University of Kentucky, shuo.tang@uky.edu \\ Martha Floy \\ Kansas State University \\ Rohit Bhandari \\ University of Kentucky, rohit.bhandari@uky.edu \\ Manjula Sunkara \\ University of Kentucky, manjula.sunkara@uky.edu \\ Andrew J. Morris \\ University of Kentucky, a.j.morris@uky.edu \\ Follow this and additional works at: https://uknowledge.uky.edu/cme_facpub \\ Part of the Biomedical Commons, Chemical Engineering Commons, Materials Chemistry Commons, \\ See next page for additional authors \\ and the Materials Science and Engineering Commons
}

Right click to open a feedback form in a new tab to let us know how this document benefits you.

\section{Repository Citation}

Tang, Shuo; Floy, Martha; Bhandari, Rohit; Sunkara, Manjula; Morris, Andrew J.; Dziubla, Thomas D.; and Hilt, J. Zach, "Synthesis and Characterization of Thermoresponsive Hydrogels Based on

$\mathrm{N}$-Isopropylacrylamide Crosslinked with 4,4'-Dihydroxybiphenyl Diacrylate" (2017). Chemical and Materials Engineering Faculty Publications. 36.

https://uknowledge.uky.edu/cme_facpub/36

This Article is brought to you for free and open access by the Chemical and Materials Engineering at UKnowledge. It has been accepted for inclusion in Chemical and Materials Engineering Faculty Publications by an authorized administrator of UKnowledge. For more information, please contact UKnowledge@lsv.uky.edu. 


\section{Synthesis and Characterization of Thermoresponsive Hydrogels Based on $\mathrm{N}$-Isopropylacrylamide Crosslinked with 4,4'-Dihydroxybiphenyl Diacrylate}

Digital Object Identifier (DOI)

https://doi.org/10.1021/acsomega.7b01247

Notes/Citation Information

Published in ACS Omega, v. 2, issue 12, p. 8723-8729.

Copyright @ 2017 American Chemical Society

This is an open access article published under an ACS AuthorChoice License, which permits copying and redistribution of the article or any adaptations for non-commercial purposes.

Authors

Shuo Tang, Martha Floy, Rohit Bhandari, Manjula Sunkara, Andrew J. Morris, Thomas D. Dziubla, and J. Zach Hilt 


\title{
Synthesis and Characterization of Thermoresponsive Hydrogels Based on N-Isopropylacrylamide Crosslinked with 4,4'- Dihydroxybiphenyl Diacrylate
}

\author{
Shuo Tang, ${ }^{\dagger, \|}$ Martha Floy, ${ }^{\ddagger}$ Rohit Bhandari, ${ }^{\dagger, \|}$ Manjula Sunkara, ${ }^{\S, \|}$ Andrew J. Morris, ${ }^{\S, \|}$
} Thomas D. Dziubla, ${ }^{\dagger, \| \odot}$ and J. Zach Hilt ${ }^{*}, \dagger, \|_{\odot}$

${ }^{\dagger}$ Department of Chemical and Materials Engineering, University of Kentucky, 177 F. Paul Anderson Tower, Lexington, Kentucky 40506, United States

${ }^{\ddagger}$ Department of Chemical Engineering, Kansas State University, 1005 Durland Hall 1701A Platt Street, Manhattan, Kansas 66506, United States

${ }^{\S}$ Division of Cardiovascular Medicine, The Gill Heart Institute, University of Kentucky, 741 S. Limestone Street, Lexington, Kentucky 40506, United States

"Superfund Research Center, University of Kentucky, 900 S. Limestone Street, Lexington, Kentucky 40536, United States

Supporting Information

ABSTRACT: A novel crosslinker [4,4'-dihydroxybiphenyl diacrylate (44BDA)] was developed, and a series of temperature-responsive hydrogels were synthesized through free radical polymerization of $\mathrm{N}$-isopropylacrylamide (NIPAAm) with 44BDA. The temperature-responsive behavior of the resulting gels was characterized by swelling studies, and the lower critical solution temperature (LCST) of the hydrogels was characterized through differential scanning calorimetry. Increased content of 44BDA led to a decreased swelling ratio and shifted the LCST to lower temperatures. These novel hydrogels also displayed resiliency through multiple swellingdeswelling cycles, and their temperature responsiveness was reversible. The successful synthesis of NIPAAm-based hydrogels crosslinked with 44BDA has led to a new class of temperature-responsive hydrogel systems with a variety of potential applications.

\section{INTRODUCTION}

Hydrogels are crosslinked three-dimensional polymeric networks that swell in aqueous solution but do not dissolve. ${ }^{1,2}$ Stimuli-responsive hydrogels exhibit swelling behavior that changes in response to environmental factors such as $\mathrm{pH}$, salt concentration, temperature, etc. ${ }^{3-6}$ These "smart" hydrogels have attracted much attention due to their variety of applications in biomedicine, ${ }^{1,7}$ drug delivery, ${ }^{2,8,9}$ tissue engineering, $^{10,11}$ separation processes, ${ }^{12}$ wastewater treatment, $^{13-15}$ etc.

Temperature-responsive hydrogels, especially the ones based on $\mathrm{N}$-isopropylacrylamide (NIPAAm), are particularly appealing because of their unique properties. NIPAAm-based polymers typically exhibit a well-defined lower critical solution temperature (LCST) at $32{ }^{\circ} \mathrm{C}$ in aqueous solution, at which hydrogen bonds form/break between water molecules and the NIPAAm chain, followed by hydration/dehydration of the network. ${ }^{8,11,16}$ The fine balance between hydrophobic-hydrophilic nature causes the swelling behavior of NIPAAm hydrogels to change significantly over a narrow temperature

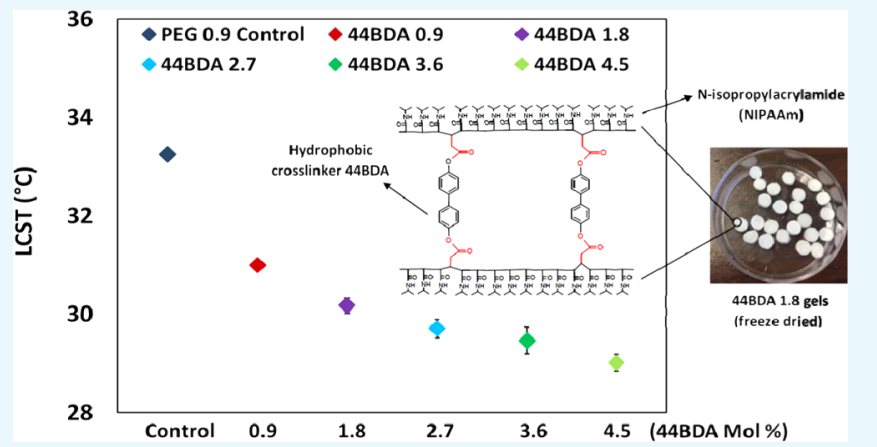

range. ${ }^{17}$ This temperature-modulated swelling property has been applied to develop an on-off switch for various activities such as drug delivery, controlled release, etc. ${ }^{14,18,19}$ In addition, the LCST can be modified through incorporating a hydrophobic or hydrophilic comonomer/crosslinker to adjust the hydrophilic-hydrophobic balance within the polymer. Usually, biomedical applications require the LCST to be between ambient temperature and body temperature $\left(\sim 37^{\circ} \mathrm{C}\right)$ or even above body temperature. The incorporation of hydrophilic compounds such as methacrylic acid, ${ }^{20,21} \mathrm{~N}$-hydroxyethylacrylamide, ${ }^{2,22}$ and acrylic acid ${ }^{3,18,23}$ has been demonstrated to raise the LCST. In regard to such studies, Lue et al. showed that addition of $2.7 \mathrm{~mol} \%$ hydrophilic acrylic acid to poly-NIPAAmbased gels increased the LCST from 34.82 to $43.96{ }^{\circ} \mathrm{C}$. $^{3}$ For other research, such as separation processes, it is potentially desirable to lower the LCST closer to ambient temperatures, so

Received: August 24, 2017

Accepted: November 21, 2017

Published: December 7, 2017 
(a)

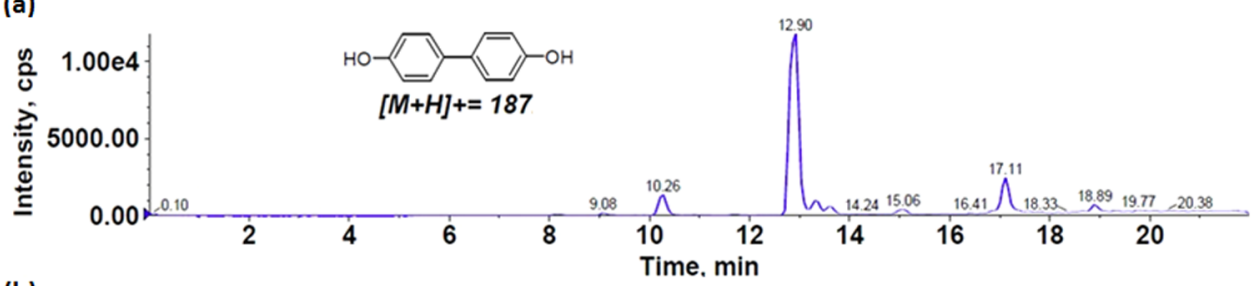

(b)

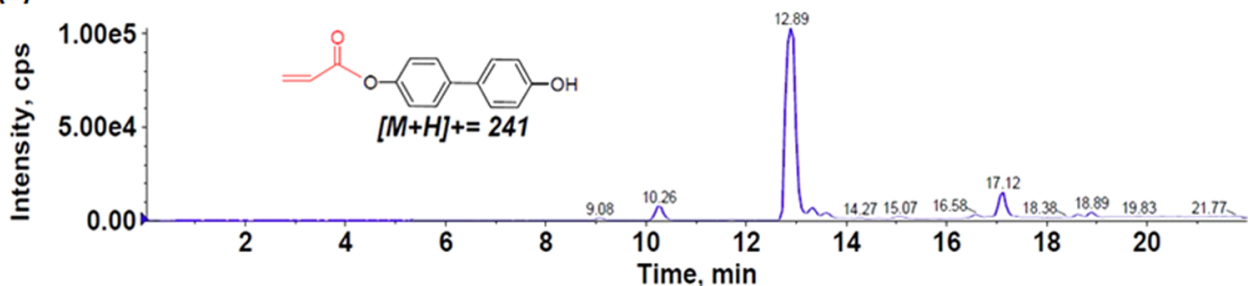

(c)

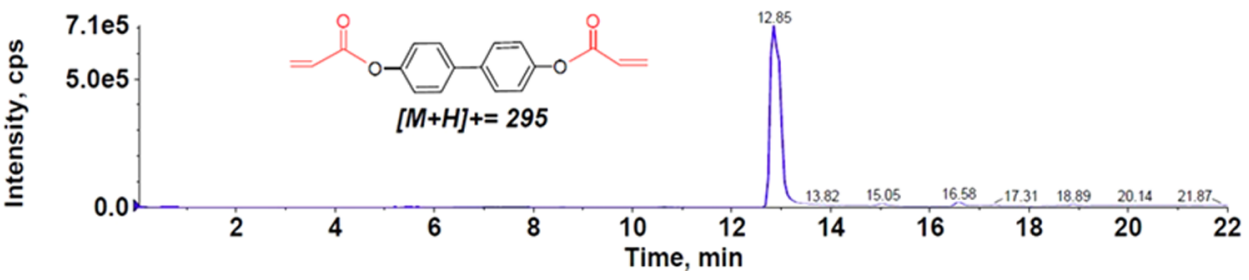

Figure 1. LC-TOF spectroscopy of (a) 4,4'-dihydroxybiphenyl, (b) monoacrylate, and (c) diacrylate.

that large energy input is not needed to drive the transition. The incorporation of hydrophobic comonomers has been reported by several studies, for example, di- $n$-propylacrylamide, ${ }^{24}$ methyl methacrylate, ${ }^{25}$ and butylmethacrylate (BMA). ${ }^{26}$ Bae et al. reported a shift of LCST to $\sim 17{ }^{\circ} \mathrm{C}$ after the addition of $10 \mathrm{~mol} \%$ of BMA. ${ }^{26}$

We synthesized NIPPAm-based thermoresponsive hydrogels using a novel crosslinker, 4,4'-dihydroxybiphenyl diacrylate (44BDA). 44BDA is synthesized from $4,4^{\prime}$-dihydroxybiphenyl, which is an aromatic hydrocarbon derivative. ${ }^{27,28} 4,4^{\prime}$ Dihydroxybiphenyl is known to work as a mesogen in combination with aliphatic dibasic acids to synthesize thermotropic liquid crystal polyesters, which have been reported to exhibit a unique odd-even effect. ${ }^{29-31}$ Beyond that, Chung et al. reported several studies using 4,4'dihydroxybiphenyl as a tyrosinase inhibitor for skin whitening purposes in the field of cosmetics. ${ }^{32,33}$ This present work focuses specifically on the synthesis and characterization of 44BDA and NIPAAm-based temperature-responsive hydrogels that use 44BDA as a crosslinker. In this paper, we have studied the effects of 44BDA content on the swelling behavior and LCST of NIPAAm hydrogels. The goal of incorporating 44BDA was to decrease the LCST while maintaining the temperature-responsive behaviors of NIPAAm gels and to introduce the unique biphenyl functionality to the network, which could potentially be useful for environmental remediation. This is the first report of the synthesis of 44BDA, as well as 44BDA-crosslinked NIPAAm hydrogels.

\section{RESULTS AND DISCUSSION}

2.1. Structural Analysis of 44BDA by Liquid Chromatography Time-of-Flight (LC-TOF) Mass Spectrometry. Upon reaction of 4,4'-dihydroxybiphenyl (precursor) with acryloyl chloride, hydroxyl groups were replaced by acrylate groups, and depending on the number of hydroxyl groups that were replaced, two forms of acrylated product could be produced: 4,4'-dihydroxybiphenyl monoacrylate and 4,4'dihydroxybiphenyl diacrylate. To determine the average molecular weight of the resulting product, LC-TOF was used to identify different forms of the acrylate and their corresponding percentages, with the results shown in Figure 1. Determining the average molecular weight is critical because it is used in the following calculations for gel synthesis. The major peak present at $12.9 \mathrm{~min}$ with a molecular weight of $295 \mathrm{~g} / \mathrm{mol}$ corresponds to $44 \mathrm{BDA}$, and the peak intensity was reported as $4.97 \times 10^{7} \mathrm{cps}$. According to a previous 4,4'-dihydroxybiphenyl partial acrylation study, the 4,4'-dihydroxybiphenyl monoacrylate and precursor had peaks at around 9 and $6 \mathrm{~min}$, respectively (see Supporting Information). Referencing the partial acrylation results, the minimal peak at 9.08 min shown in Figure $1 \mathrm{a}, \mathrm{b}$ corresponds to $4,4^{\prime}$-dihydroxybiphenyl monoacrylate. There was no measurable peak around $6 \mathrm{~min}$ in Figure $1 \mathrm{a}-\mathrm{c}$ corresponding to the precursor, which is likely due to the addition of an excess amount of acryloyl chloride (3:1, and 1 mole of 4,4'-dihydroxybiphenyl only reacts with 2 moles of acryloyl chloride (AC)). The excess addition of acryloyl chloride resulted in approximately $100 \%$ conversion of the precursor to the diacrylate product, leaving 4,4'-dihydroxybiphenyl (with a molecular weight of $187 \mathrm{~g} / \mathrm{mol}$ ) and 4,4'dihydroxybiphenyl monoacrylate (with a molecular weight of $241 \mathrm{~g} / \mathrm{mol}$ ) with no measurable contribution. Two minor peaks present at 10.26 and $17.11 \mathrm{~min}$ might be associated with impurities left in 44BDA, which could either be side products from acrylation or impurities in the precursor. Because of the approximate $100 \%$ conversion of $4,4^{\prime}$-dihydroxybiphenyl to 44BDA, the average molecular weight of 44BDA was considered to be $295 \mathrm{~g} / \mathrm{mol}$.

2.2. High Performance Liquid Chromatography (HPLC). A combined HPLC chromatogram for 4,4'-dihydroxybiphenyl and 44BDA is shown in Figure 2. The blue and green lines represent the chromatograms for 4,4'-dihydroxybiphenyl and 44BDA, respectively. The major peak observed in the blue 


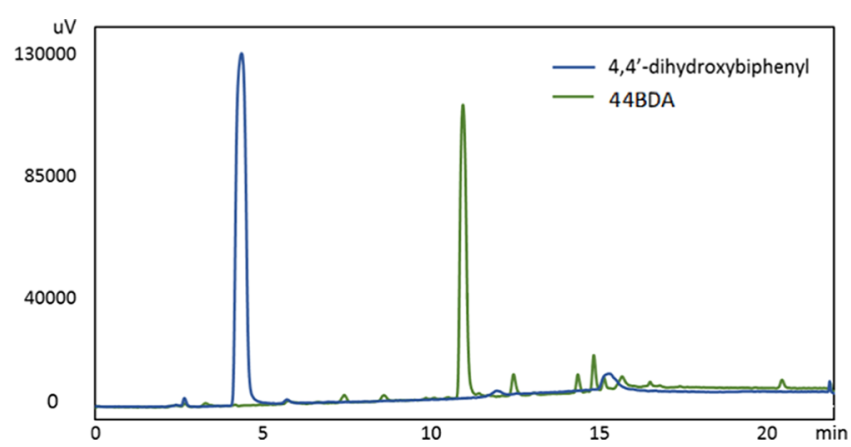

Figure 2. HPLC chromatograms for 4,4'-dihydroxybiphenyl and 44BDA.

line shown at $4.5 \mathrm{~min}$ is associated with the characteristic peak of 4,4'-dihydroxybiphenyl. No peak was observed at $4.5 \mathrm{~min}$ in the case of 44BDA (green line), indicating all starting material was converted to the acrylated forms. On the basis of an increase in hydrophobicity of the acrylated forms of 4,4'dihydroxybiphenyl, the major peak in 44BDA shown at $11 \mathrm{~min}$ can be attributed to either the mono- or diacrylate of 44BDA. Because of the excess acryloyl chloride addition during synthesis, the reaction was pushed further to produce almost $100 \%$ diacrylate. Thus, on the basis of our analysis, the peak could be assigned to 44BDA instead of 4,4'-dihydroxybiphenyl monoacrylate, and these results were observed to be in accordance with the LC-TOF data discussed in the previous section.

2.3. Synthesis of NIPAAm Gels Crosslinked with 44BDA. Five different 44BDA-crosslinked NIPAAm gels and a poly(ethylene glycol) (PEG) comparison group were prepared via free radical polymerization. The acrylate groups on 44BDA allow for the crosslinking with the NIPAAm chain resulting in the network structure. Prior to gel synthesis, reaction conditions (temperature, time, $\mathrm{N}_{2}$ purging) were optimized.

2.4. Swelling Studies. The kinetic swelling behavior of 44BDA gels was studied at $25{ }^{\circ} \mathrm{C}$. A plot of swelling ratio versus time (Figure 3 ) shows that the gels reach equilibrium swelling by $24 \mathrm{~h}$. For all swelling studies reported in this work, NIPAAm

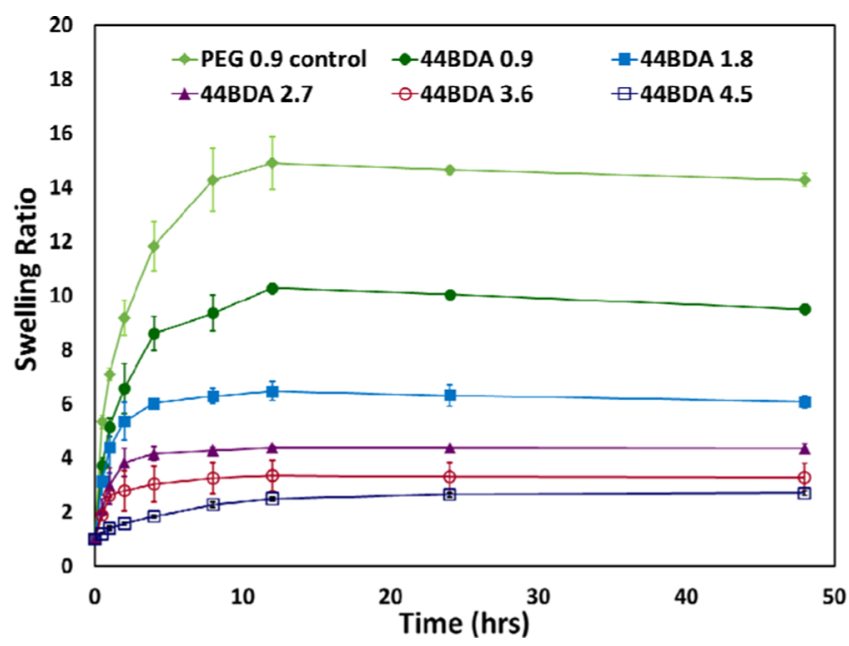

Figure 3. Kinetic swelling study of PEG control gel and 44BDA gel set, error bars represent average swelling ratio \pm standard deviation where $n=3$. crosslinked with $0.9 \mathrm{~mol} \%$ of PEG400DMA was chosen as a comparison group for the 44BDA gels, and it was labeled as PEG 0.9 control. PEG multiacrylates and multimethacrylates are commonly used crosslinkers, and they have been reported in several studies. ${ }^{34-36}$ From Figure 3, it can be observed that the equilibrium swelling ratio decreased significantly with increasing 44BDA content, as expected. The PEG400DMA comparison group had the highest swelling ratio, because PEG400DMA is less hydrophobic than 44BDA.

The temperature-dependent swelling profiles of the NIPAAm-based hydrogels with varying amounts of 44BDA are illustrated in Figure 4. As temperature increased, swelling

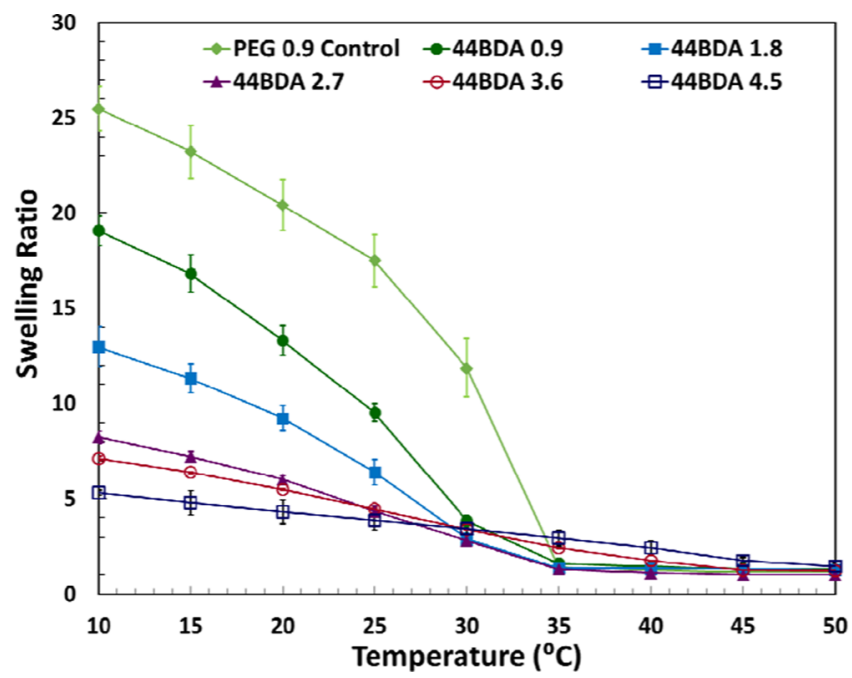

Figure 4. Temperature-dependent swelling profiles of PEG control gel and 44BDA gel set, error bars represent average swelling ratio \pm standard deviation where $n=3$.

decreased until $50{ }^{\circ} \mathrm{C}$, when all gels completely collapsed. The swelling ratio decreased significantly between 25 and $35{ }^{\circ} \mathrm{C}$, where the phase transitions were observed. The transition temperatures shifted away from the LCST of NIPAAm (32-33 ${ }^{\circ} \mathrm{C}$ ), which was expected, as addition of a hydrophobic crosslinker should shift the transition temperature to lower temperatures. Higher 44BDA-content gels showed broader phase transitions than those of the lower content ones, which was due to their higher crosslinking degrees in the gel structure. This can especially be seen in the 44BDA 3.6 and 4.5 gels, which require a temperature of $50{ }^{\circ} \mathrm{C}$ to collapse completely, whereas the lower-crosslinked ones collapsed completely at 35 ${ }^{\circ} \mathrm{C}$. Comparable investigations by Inomata et al. and Tang et al. ${ }^{37,38}$ also confirmed that the transition range is influenced by crosslinking density.

Reversible temperature response, which reveals the potential reusability of a gel, is important for applications of hydrogels. In this study, reversible temperature changes were designed to span the LCST of the gels alternating between 10 and $50{ }^{\circ} \mathrm{C}$, where gels went from being almost completely swollen to completely collapsed. A plot of swelling ratio versus temperature is shown in Figure 5. It was found that the gel reswelling ratios at $10{ }^{\circ} \mathrm{C}$ for the second and third cycle were very similar to the initial swelling ratio, indicating that the swelling-collapse process of the gels was reversible.

2.5. LCST Measurements. The LCSTs of the PEG control and 44BDA gels were measured by differential scanning calorimetry (DSC). Results from the analysis are shown in 


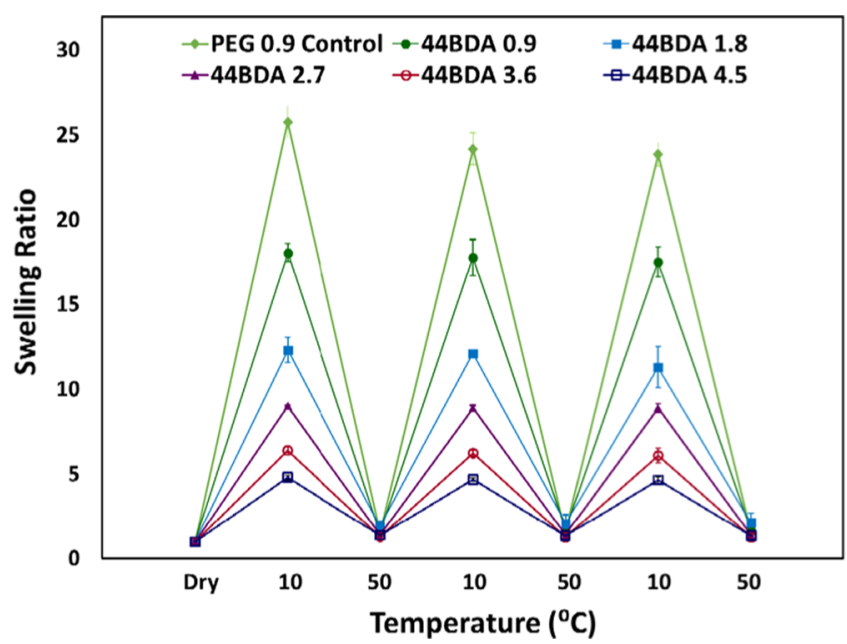

Figure 5. Reversible swelling profile of PEG control gel and 44BDA gel set, error bars represent average swelling ratio \pm standard deviation where $n=3$.

Figure 6a for example thermograms and (b) for LCST values. Endothermic peaks in the thermograms represent the LCST where intramolecular hydrogen bonds are broken requiring heat. ${ }^{3}$ PEG 0.9 control gel showed a LCST of $32.8{ }^{\circ} \mathrm{C}$, which was within the range of previously reported literature values for homopolymer NIPAAm $\left(32-33^{\circ} \mathrm{C}\right) .{ }^{16,39-41}$ It is expected that the incorporation of hydrophobic comonomers or crosslinkers will decrease the amount of intermolecular hydrogen bonding, resulting in less heat being required to break the hydrogen bonds and resulting in a decrease in LCST. From Figure 6, the LCST of the gels showed the expected decrease with increasing amounts of 44BDA, and the LCST shifted up $4.3{ }^{\circ} \mathrm{C}$ from that of the PEG control $\left(32.8{ }^{\circ} \mathrm{C}\right)$ to that of the 44BDA 4.5 gel $\left(28.5{ }^{\circ} \mathrm{C}\right)$.

\section{CONCLUSIONS}

The hydrophobic crosslinker 44BDA was successfully synthesized, and NIPAAm was reacted with this novel crosslinker to form temperature-responsive hydrogels through free radical polymerization. 44BDA content in the hydrogel was varied from 0.9 to $4.5 \mathrm{~mol} \%$, and its effect on hydrogel swelling behavior and LCST was studied. As more 44BDA was incorporated, hydrogels showed decreased swelling ratios, and the difference was especially significant in the low temperature region. Meanwhile, their LCSTs were shifted to lower temperatures with increasing 44BDA. Higher 44BDA content gels exhibited broader phase transitions due to a high degree of crosslinking. A reversible response to temperature change was seen for those hydrogels, indicating good reusability for various applications including environmental remediation.

\section{EXPERIMENTAL SECTION}

4.1. Materials. 4,4'-Dihydroxybiphenyl, triethyl amine (TEA), acryloyl chloride (AC), N-isopryopylacrylamide (NIPAAm, 97\%), and ammonium persulfate (APS, $\geq 98 \%$ ) were purchased from Sigma-Aldrich Corporation (St. Louis). Poly(ethylene glycol) 400 dimethacrylate (PEG400DMA) was purchased from Polysciences, Inc. (Warrington). All solvents (dimethyl sulfoxide (DMSO), acetone, tetrahydrofuran (THF), dichloromethane (DCM), and acetonitrile $(\mathrm{ACN})), \mathrm{HCl}$, $\mathrm{K}_{2} \mathrm{CO}_{3}$, and magnesium sulfate were purchased from VWR International (Radnor). Molecular sieves ( $3 \AA$ ) were added to the solvents to remove any moisture present and to maintain the anhydrous state of the solvents. Crosslinker 44BDA was synthesized in the lab by acrylation of 4,4'-dihydroxybiphenyl.

4.2. Synthesis of 44BDA. 44BDA was synthesized using a modification to a method reported previously. ${ }^{42}$ Briefly, $4,4^{\prime}$ dihydroxybiphenyl was dissolved in an excess amount of THF, followed by the addition of TEA and AC with the ratio of TEA/AC/4,4'-dihydroxybiphenyl of 3:3:1. AC was added dropwise under continuous stirring in an ice bath. The acrylation process was allowed to proceed overnight under dark conditions. The mixture was then subjected to vacuum filtration to remove the precipitated triethylammonium chloride salts. Next, THF from the filtrate was evaporated under vacuum using a liquid $\mathrm{N}_{2}$ trap. The recovered 44BDA was redissolved in DCM and purified by multiple washes with $0.1 \mathrm{M} \mathrm{K}_{2} \mathrm{CO}_{3}$ and then $0.1 \mathrm{M} \mathrm{HCl}$ to remove any unreacted $\mathrm{AC}$ and TEA. Then, magnesium sulfate was added to remove any remaining water from the solution, followed by the second filtration of the product. The final mixture was evaporated again under vacuum (a)

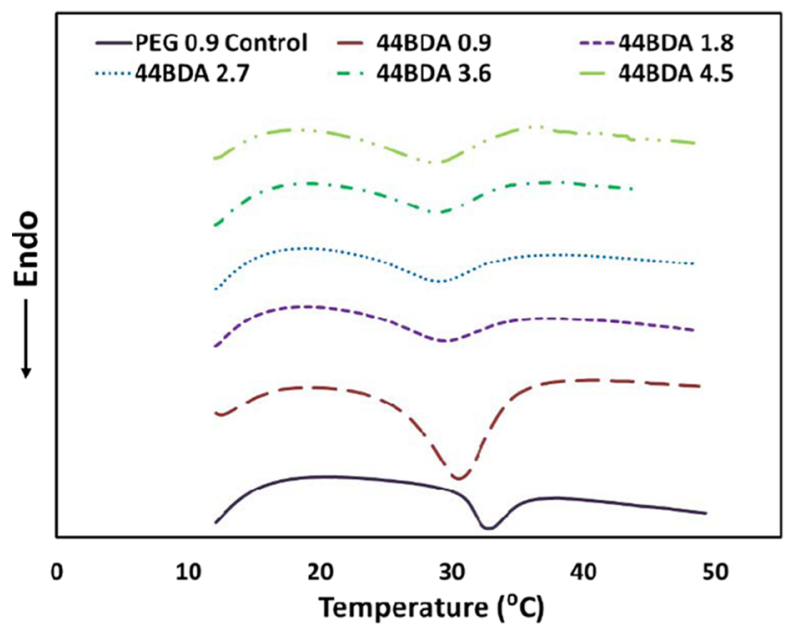

(b)

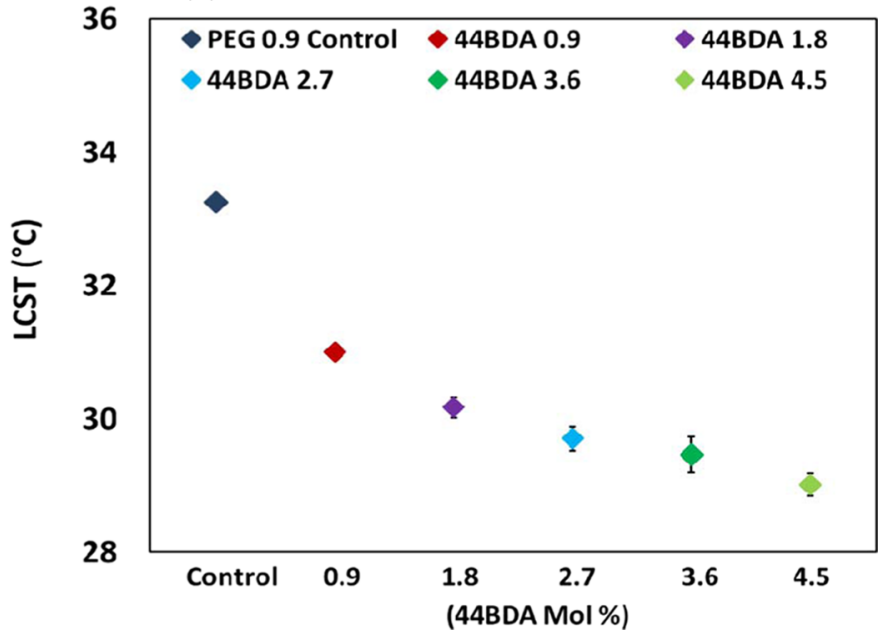

Figure 6. (a) Sample DSC thermogram of PEG control gel and 44BDA gel set. (b) Numerical values of PEG control gel and 44BDA gel set, error bars represent average LCST \pm standard deviation where $n=3$. 


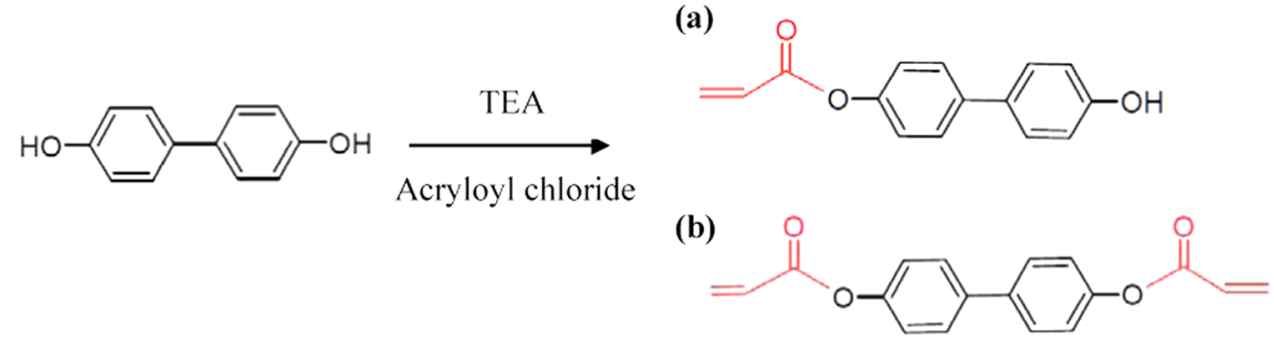

Figure 7. Chemical structures of 4,4'-dihydroxybiphenyl and the two forms of acrylate. (a) 4,4'-Dihydroxybiphenyl monoacrylate and (b) 4,4'dihydroxybiphenyl diacrylate.

Scheme 1. Schematic Showing the Polymerization Reaction and Polymeric Network of NIPAAm-co-44BDA Gel

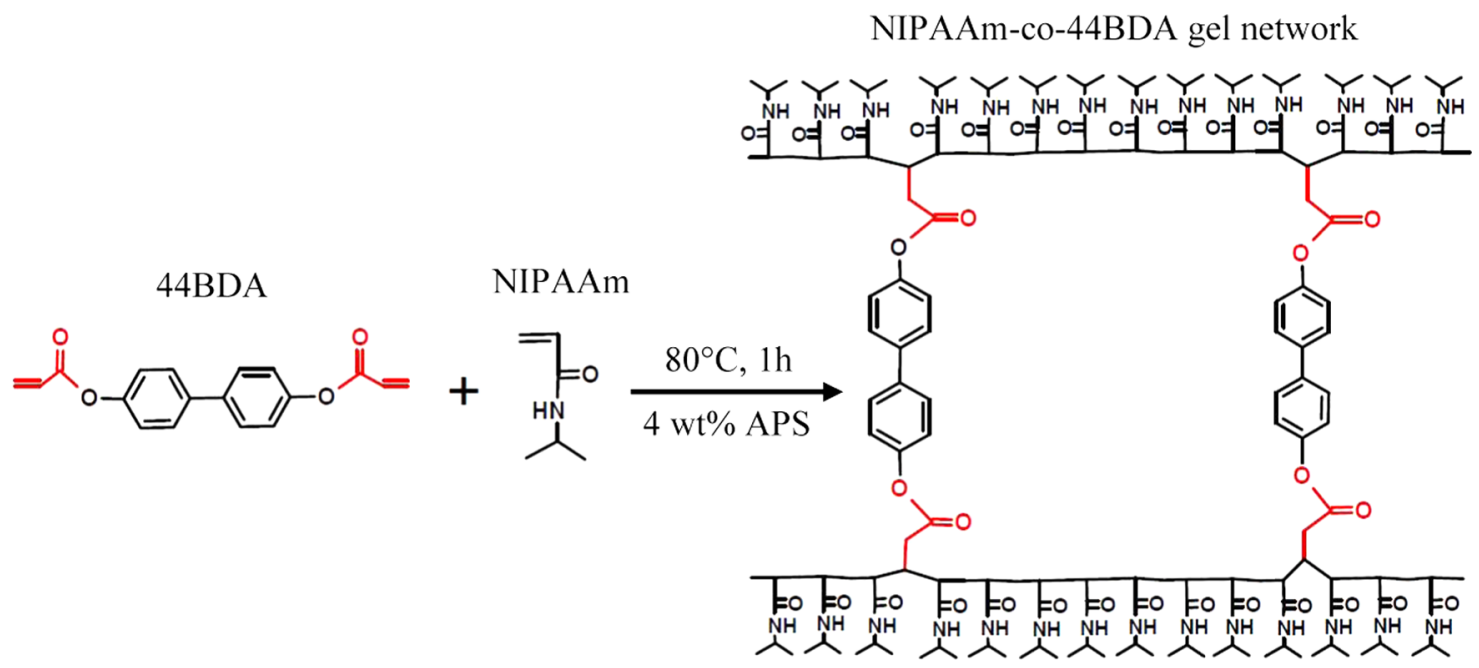

Table 1. Feed Composition of PEG Control and 44BDA Gels

\begin{tabular}{|c|c|c|c|c|c|c|c|c|c|c|}
\hline sample & $\underset{(\mathrm{mol} \%)}{\text { NIPAAm }}$ & $\begin{array}{l}\text { 44BDA } \\
(\mathrm{mol} \%)\end{array}$ & $\begin{array}{l}\text { PEG400DMA } \\
(\mathrm{mol} \%)\end{array}$ & $\begin{array}{l}\text { NIPAAm } \\
(\mathrm{mg})\end{array}$ & $\begin{array}{c}\text { 44BDA } \\
(\mathrm{mg})\end{array}$ & $\begin{array}{l}\text { PEG400DMA } \\
(\mathrm{mg})\end{array}$ & $\begin{array}{c}\text { DMSO } \\
(\mathrm{mL})\end{array}$ & $\begin{array}{l}\text { APS } \\
(\mathrm{mg})\end{array}$ & $\begin{array}{l}\text { total mass } \\
(\mathrm{mg})\end{array}$ & $\begin{array}{c}\text { NIPAAm }+44 \mathrm{BDA} \\
(\mathrm{wt} \%)\end{array}$ \\
\hline PEG 0.9 & 99.1 & & 0.9 & 280.4 & & 10.3 & 1 & 11.6 & 1402.3 & 20.7 \\
\hline 44BDA 0.9 & 99.1 & 0.9 & & 280.4 & 6.6 & & 1 & 11.5 & 1398.5 & 20.5 \\
\hline 44BDA 1.8 & 98.2 & 1.8 & & 277.8 & 13.3 & & 1 & 11.6 & 1402.7 & 20.8 \\
\hline 44BDA 2.7 & 97.3 & 2.7 & & 275.3 & 19.9 & & 1 & 11.8 & 1407.0 & 21.0 \\
\hline 44BDA 3.6 & 96.4 & 3.6 & & 272.7 & 26.6 & & 1 & 12.0 & 1411.2 & 21.2 \\
\hline 44BDA 4.5 & 95.5 & 4.5 & & 270.2 & 33.2 & & 1 & 12.1 & 1415.5 & 21.4 \\
\hline
\end{tabular}

using a liquid $\mathrm{N}_{2}$ trap to obtain a dry powdered product, and this was stored at $-20{ }^{\circ} \mathrm{C}$ until use. A combination of monoand diacrylates was obtained (see Figure 7 for their structures).

4.3. Confirming the Acrylation through High Performance Liquid Chromatography. The synthesized 44BDA was characterized using reverse-phase HPLC (Waters Phenomenex C18 column, $5 \mu \mathrm{m}, 250 \mathrm{~mm}$ (length) $\times 4.6 \mathrm{~mm}$ (I.D.) on a Shimadzu Prominence LC-20 AB HPLC system). Samples were dissolved in $\mathrm{ACN}$ at $100 \mu \mathrm{g} / \mathrm{mL}$. A gradient from $50 / 50$ $\mathrm{ACN} /$ water to $100 / 0 \mathrm{ACN} /$ water over $24 \mathrm{~min}$ at $1 \mathrm{~mL} / \mathrm{min}$ was used with the column chamber set at $40{ }^{\circ} \mathrm{C}$. The absorbance was measured from 260 to $370 \mathrm{~nm}$.

4.4. Characterizing the Molecular Weight of 44BDA through Liquid Chromatography Time-of-Flight. Analysis of 44BDA was carried out using a Shimadzu HPLC coupled with a Sciex TripleTOF 5600 quadrupole time-of-flight mass spectrometer. 44BDA was analyzed using a Zorbax Eclipse XDB C18 column, $5 \mu \mathrm{M}, 4.6 \times 150 \mathrm{~mm}$ column (Agilent). The mobile phase consisted of water with $0.1 \%$ TEA as solvent A and $\mathrm{ACN}$ with $0.1 \%$ TEA as solvent $\mathrm{B}$. The flow rate was 0.5
$\mathrm{mL} / \mathrm{min}$ with a column temperature of $30{ }^{\circ} \mathrm{C}$. The sample injection volume was $10 \mu \mathrm{L}$. The mass spectrometer was operated in the positive electrospray ionization mode with a curtain gas of $20 \mathrm{psi}$, ion spray voltage of $5500 \mathrm{~V}$, ion source gas $1 /$ gas 2 of 40 psi and temperature of $550{ }^{\circ} \mathrm{C}$.

4.5. Synthesis of NIPAAm-co-44BDA Hydrogels. All gels were synthesized through free radical polymerization (schematic in Scheme 1). A control system was synthesized by crosslinking NIPAAm with 0.9 mol \% of PEG400DMA. The 44BDA system was crosslinked with NIPAAm at five different compositions (0.9, 1.8, 2.7, 3.6, and $4.5 \mathrm{~mol} \%)$. For example, the 44BDA 0.9 gel was synthesized by dissolving $6.6 \mathrm{mg}$ of 44BDA with $280 \mathrm{mg}$ of NIPAAm in $1 \mathrm{~mL}$ of DMSO. The initiator, APS, was dissolved in DI water $(0.5 \mathrm{mg} / \mathrm{mL})$ and added at 4 wt $\%$ combined weight of NIPAAm and 44BDA. The monomer and reactant solution was vortexed and purged with nitrogen for $5 \mathrm{~min}$. The mixture was then equally divided into five shell vials with the top covered by a rubber stopper and allowed to react in a preheated $80{ }^{\circ} \mathrm{C}$ water bath for $1 \mathrm{~h}$. To remove any unreacted monomers, the gel was washed with 
excess acetone followed by DI water (three times each for 30 min per wash). Then, the gels were cut into small pieces and freeze dried for $24 \mathrm{~h}$ until no further mass change occurred. Reaction components for all other gels have been summarized in Table 1.

4.6. Swelling Studies. A series of swelling studies were performed to test the swelling properties of the 44BDA gels. First, the gels were swelled in DI water at $25{ }^{\circ} \mathrm{C}$ in an isothermal water bath to study the equilibrium swelling kinetics. Mass measurements were taken at time points of $0,0.5,1,2,4$, $8,12,24$, and $48 \mathrm{~h}$. The swelling ratio was defined as swollen mass divided by dry mass as shown in eq 1 .

$$
q=M_{\text {swollen }} / M_{\text {dry }}
$$

Once the equilibrium swellings were obtained, a temperaturedependent swelling study was conducted to determine the swelling profile for each composition. In this study, gels were swelled at temperature increments of $5{ }^{\circ} \mathrm{C}$ from 10 to $50{ }^{\circ} \mathrm{C}$ for $24 \mathrm{~h}$ to reach equilibrium swelling, and mass swelling ratios at each temperature were calculated. In this study, gels were placed through three cycles in an isothermal water bath from swollen state at $10{ }^{\circ} \mathrm{C}$ to a collapsed state at $50{ }^{\circ} \mathrm{C}$, and mass swelling ratios were recorded at each temperature after $24 \mathrm{~h}$ of swelling.

4.7. LCST Measurements. The LCSTs of the hydrogels were measured using differential scanning calorimetry (DSC Q200, TA instruments Inc., New Castle). Hydrogels were allowed to swell completely for at least $24 \mathrm{~h}$ in DI water. A small piece of gel was gently dabbed dry, placed in a T-zero pan, and the mass was carefully recorded. The sample was hermetically sealed in the T-zero pan and placed along with a reference pan on the heater. Samples were then heated from 10 to $50{ }^{\circ} \mathrm{C}$ at a rate of $2{ }^{\circ} \mathrm{C} / \mathrm{min}$ under a dry nitrogen atmosphere at a flow rate of $50 \mathrm{~mL} / \mathrm{min}$.

\section{ASSOCIATED CONTENT}

\section{S Supporting Information}

The Supporting Information is available free of charge on the ACS Publications website at DOI: 10.1021/acsomega.7b01247.

LC-TOF spectrum of a 4,4'-dihydroxybiphenyl partial acrylation study, TEA/AC/4, $4^{\prime}$-dihydroxybiphenyl was $2: 2: 1$ instead of $3: 3: 1$ in the full acrylation synthesis (PDF)

\section{AUTHOR INFORMATION}

\section{Corresponding Author}

*E-mail: zach.hilt@uky.edu.

\section{ORCID}

Thomas D. Dziubla: 0000-0003-2518-3926

J. Zach Hilt: 0000-0001-5780-6847

Notes

The authors declare no competing financial interest.

\section{ACKNOWLEDGMENTS}

This research has been generously supported by the NSF-REU grant EEC-1460486 and the NIEHS/NIH grant P42ES007380. The content is solely the responsibility of the authors and does not necessarily represent the official views of $\mathrm{NIH}$.

\section{ABBREVIATIONS}

NIPAAm, N-isopropylacrylamide; 44BDA, 4,4'-dihyroxybiphenyl diacrylate; LCST, lower critical solution temperature

\section{REFERENCES}

(1) Klouda, L. Thermoresponsive hydrogels in biomedical applications: a seven-year update. Eur. J. Pharm. Biopharm. 2015, 97, 338-349.

(2) Bucatariu, S.; Fundueanu, G.; Prisacaru, I.; Balan, M.; Stoica, I.; Harabagiu, V.; Constantin, M. Synthesis and characterization of thermosensitive poly (N-isopropylacrylamide-co-hydroxyethylacrylamide) microgels as potential carriers for drug delivery. J. Polym. Res. 2014, 21, 1-12.

(3) Lue, S. J.; Chen, C.-H.; Shih, C.-M. Tuning of lower critical solution temperature (LCST) of poly ( $\mathrm{N}$-isopropylacrylamide-coacrylic acid) hydrogels. J. Macromol. Sci., Part B 2011, 50, 563-579.

(4) Lee, W.-F.; Hsu, C.-H. Thermoreversible hydrogels: 3. Synthesis and swelling behavior of the ( $\mathrm{N}$-isopropylacrylamide-co-trimethylacrylamidopropyl ammonium iodide) copolymeric hydrogels. Polymer 1998, 39, 5393-5403.

(5) Brazel, C. S.; Peppas, N. A. Synthesis and Characterization of Thermo-and Chemomechanically Responsive Poly (N-isopropylacrylamide-co-methacrylic acid) Hydrogels. Macromolecules 1995, 28, 8016-8020.

(6) Kim, J. H.; Lee, S. B.; Kim, S. J.; Lee, Y. M. Rapid temperature/ $\mathrm{pH}$ response of porous alginate-g-poly ( $\mathrm{N}$-isopropylacrylamide) hydrogels. Polymer 2002, 43, 7549-7558.

(7) Yoo, M. K.; Seok, W. K.; Sung, Y. K. In Characterization of Stimuli-Sensitive Polymers for Biomedical Applications; Macromolecular Symposia; Wiley Online Library, 2004; pp 173-186.

(8) Díez-Peña, E.; Frutos, P.; Frutos, G.; Quijada-Garrido, I.; Barrales-Rienda, J. M. The influence of the copolymer composition on the diltiazem hydrochloride release from a series of $\mathrm{pH}$-sensitive poly [(N-isopropylacrylamide)-co-(methacrylic acid)] hydrogels. AAPS PharmSciTech 2004, 5, 69-76.

(9) Fu, G.; Soboyejo, W. Swelling and diffusion characteristics of modified poly (N-isopropylacrylamide) hydrogels. Mater. Sci. Eng., C 2010, 30, 8-13.

(10) Ashraf, S.; Park, H.-K.; Park, H.; Lee, S.-H. Snapshot of phase transition in thermoresponsive hydrogel PNIPAM: Role in drug delivery and tissue engineering. Macromol. Res. 2016, 24, 297-304.

(11) Stile, R. A.; Burghardt, W. R.; Healy, K. E. Synthesis and characterization of injectable poly ( $\mathrm{N}$-isopropylacrylamide)-based hydrogels that support tissue formation in vitro. Macromolecules 1999, 32, 7370-7379.

(12) Freitas, R. F.; Cussler, E. Temperature sensitive gels as extraction solvents. Chem. Eng. Sci. 1987, 42, 97-103.

(13) Iyer, G.; Tillekeratne, L. M. V.; Coleman, M. R.; Nadarajah, A. Equilibrium swelling behavior of thermally responsive metal affinity hydrogels, Part I: Compositional effects. Polymer 2008, 49, 37373743.

(14) Parasuraman, D.; Sarker, A. K.; Serpe, M. J. Recyclability of poly ( $\mathrm{N}$-isopropylacrylamide) microgel-based assemblies for organic dye removal from water. Colloid Polym. Sci. 2013, 291, 1795-1802.

(15) Ali, W.; Gebert, B.; Hennecke, T.; Graf, K.; Ulbricht, M.; Gutmann, J. S. Design of thermally responsive polymeric hydrogels for brackish water desalination: effect of architecture on swelling, deswelling, and salt rejection. ACS Appl. Mater. Interfaces 2015, 7, 15696-15706.

(16) Zheng, X.; Tong, Z.; Xie, X.; Zeng, F. Phase separation in poly ( $\mathrm{N}$-isopropyl acrylamide)/water solutions I: Cloud point curves and microgelation. Polym. J. 1998, 30, 284-288.

(17) Prange, M. M.; Hooper, H. H.; Prausnitz, J. M. Thermodynamics of aqueous systems containing hydrophilic polymers or gels. AIChE J. 1989, 35, 803-813.

(18) Rahman, M.; Nahar, Y.; Ullah, W.; Elaissari, A.; Ahmad, H. Incorporation of iron oxide nanoparticles into temperature-responsive 
poly (N-isopropylacrylamide-co-acrylic acid) P (NIPAAm-AA) polymer hydrogel. J. Polym. Res. 2015, 22, 1-9.

(19) Bae, Y. H.; Okano, T.; Kirn, S. W. "On-Off "Thermocontrol of Solute Transport. II. Solute Release from Thermosensitive Hydrogels. Pharm. Res. 1991, 08, 624-628.

(20) Huglin, M. B.; Liu, Y.; Velada, J. Thermoreversible swelling behaviour of hydrogels based on $\mathrm{N}$-isopropylacrylamide with acidic comonomers. Polymer 1997, 38, 5785-5791.

(21) Velada, J. L.; Liu, Y.; Huglin, M. B. Effect of pH on the swelling behaviour of hydrogels based on $\mathrm{N}$-isopropylacrylamide with acidic comonomers. Macromol. Chem. Phys. 1998, 199, 1127-1134.

(22) Fundueanu, G.; Constantin, M.; Asmarandei, I.; Bucatariu, S.; Harabagiu, V.; Ascenzi, P.; Simionescu, B. C. Poly (N-isopropylacrylamide-co-hydroxyethylacrylamide) thermosensitive microspheres: The size of microgels dictates the pulsatile release mechanism. Eur. J. Pharm. Biopharm. 2013, 85, 614-623.

(23) Chiu, H.-C.; Lin, Y.-F.; Hung, S.-H. Equilibrium swelling of copolymerized acrylic acid-methacrylated dextran networks: effects of $\mathrm{pH}$ and neutral salt. Macromolecules 2002, 35, 5235-5242.

(24) Xue, W.; Hamley, I. W. Thermoreversible swelling behaviour of hydrogels based on $\mathrm{N}$-isopropylacrylamide with a hydrophobic comonomer. Polymer 2002, 43, 3069-3077.

(25) Lowe, T. L.; Virtanen, J.; Tenhu, H. Hydrophobically modified responsive polyelectrolytes. Langmuir 1999, 15, 4259-4265.

(26) Bae, Y. H.; Okano, T.; Kim, S. W. "On-Off” thermocontrol of solute transport. I. Temperature dependence of swelling of $\mathrm{N}$ isopropylacrylamide networks modified with hydrophobic components in water. Pharm. Res. 1991, 08, 531-537.

(27) Paramasivaganesh, K.; Srinivasan, K.; Manivel, A.; Anandan, S.; Sivakumar, K.; Radhakrishnan, S.; Stalin, T. Studies on inclusion complexation between $4,4^{\prime}$-dihydroxybiphenyl and $\beta$-cyclodextrin by experimental and theoretical approach. J. Mol. Struct. 2013, 1048, 399-409.

(28) Liang, R.; Zhao, Y.; Su, Y.; Qin, W. Determination of hydroxylated polychlorinated biphenyls by offline solid-phase extraction-liquid chromatography-tandem mass spectrometry using a molecularly imprinted polymer as a sorbent for sample preconcentration. Talanta 2015, 144, 115-121.

(29) Krigbaum, W.; Watanabe, J.; Ishikawa, T. Thermotropic polyesters. 2. Investigation of the mesophase properties of polymers based on 4, 4'-dihydroxybiphenyl. Macromolecules 1983, 16, 12711279.

(30) Tokita, M.; Okuda, S.; Yoshihara, S.; Takahashi, C.; Kang, S.; Sakajiri, K.; Watanabe, J. Identifying smectic I phase of main-chain PB10 polyester consisting of 4, 4'-biphenol and 1, 10-dodecanoic acid by fibre X-ray diffraction. Polymer 2012, 53, 5596-5599.

(31) Jannesari, A.; Ghaffarian, S. R.; Taromi, F. A.; Mohammadi, N. The preparation and properties of segmented-chain liquid crystalline polyesters based on 4, 4'-dihydroxybiphenyl by interfacial polycondensation. J. Appl. Polym. Sci. 2005, 98, 1594-1606.

(32) Kim, Y. J.; No, J. K.; Lee, J. H.; Chung, H. Y. 4, 4'Dihydroxybiphenyl as a new potent tyrosinase inhibitor. Biol. Pharm. Bull. 2005, 28, 323-327.

(33) No, J. K.; Kim, Y. J.; Lee, J. S.; Chung, H. Y. Inhibition of melanogenic activity by $4,4^{\prime}$-dihydroxybiphenyl in melanoma cells. Biol. Pharm. Bull. 2006, 29, 14-16.

(34) Meenach, S. A.; Anderson, K. W.; Hilt, J. Z. Synthesis and characterization of thermoresponsive poly (ethylene glycol)-based hydrogels and their magnetic nanocomposites. J. Polym. Sci., Part A: Polym. Chem. 2010, 48, 3229-3235.

(35) Kim, Y. G.; Lee, C. H.; Bae, Y. C. Hydrophilic-hydrophobic copolymer nano-sized particle gels: Swelling behavior and dependence on crosslinker chain length. Fluid Phase Equilib. 2014, 361, 200-207.

(36) Frimpong, R. A.; Hilt, J. Z. Poly (n-isopropylacrylamide)-based hydrogel coatings on magnetite nanoparticles via atom transfer radical polymerization. Nanotechnology 2008, 19, No. 175101.

(37) Inomata, H.; Wada, N.; Yagi, Y.; Goto, S.; Saito, S. Swelling behaviours of $\mathrm{N}$-alkylacrylamide gels in water: effects of copolymerization and crosslinking density. Polymer 1995, 36, 875-877.
(38) Tang, S.; Bhandari, R.; Delaney, S. P.; Munson, E. J.; Dziubla, T. D.; Hilt, J. Z. Synthesis and characterization of thermally responsive Nisopropylacrylamide hydrogels copolymerized with novel hydrophobic polyphenolic crosslinkers. Mater. Today Commun. 2017, 10, 46-53.

(39) Schild, H. Preparation of novel acrylamide-based thermoresponsive polymer analogues and their application as thermoresponsive chromatographic matrices. Prog. Polym. Sci. 1992, 17, 163-249.

(40) Hirokawa, Y.; Tanaka, T. Volume phase transition in a nonionic gel. J. Chem. Phys. 1984, 81, 6379-6380.

(41) Kuckling, D.; Wohlrab, S. Synthesis and characterization of biresponsive graft copolymer gels. Polymer 2002, 43, 1533-1536.

(42) Patil, V. S.; Dziubla, T. D.; Kalika, D. S. Static and dynamic properties of biodegradable poly (antioxidant $\beta$-amino ester) networks based on incorporation of curcumin multiacrylate. Polymer 2015, 75, $88-96$. 